\title{
New Cloud Detection Index (CDI) for Forecasting the Extreme Rain Events
}

\author{
Niket Shastri1 ${ }^{\circledR}$, Kamlesh Pathak ${ }^{2}$ \\ ${ }^{1}$ Department of Physics, Sarvajanik College of Engineering and Technology, Surat, India \\ ${ }^{2}$ Department of Physics, Sardar Vallabhbhai Institute of Technology, Surat, India \\ Email: niket.shastri@scet.ac.in
}

How to cite this paper: Shastri, N. and Pathak, K. (2019) New Cloud Detection Index (CDI) for Forecasting the Extreme Rain Events. Advances in Remote Sensing, 8, 30-39.

https://doi.org/10.4236/ars.2019.81002

Received: January 1, 2019

Accepted: March 8, 2019

Published: March 11, 2019

Copyright (c) 2019 by author(s) and Scientific Research Publishing Inc. This work is licensed under the Creative Commons Attribution International License (CC BY 4.0).

http://creativecommons.org/licenses/by/4.0/

cc) (i) Open Access

\begin{abstract}
The water vapor content and clouds play a very significant role in atmospheric conditions. This paper is derived from the new cloud detection index (CDI) which is useful to forecast extreme weather events like heavy or extreme rain. The CDI is retrieved using two crucial elements of cloud formation, the critical humidity and critical water vapor. The cloud thickness is determined by using CDI for a radiosonde site (VABB) located in Mumbai, the western part of India. The obtained results are compared with the cloud thickness required for extreme rain. The outcome of the comparison is discussed in this paper. The cloud detection index is also useful in establishing the atmospheric stability along with another four atmospheric stability indices.
\end{abstract}

\section{Keywords}

Cloud Detection Index, Water Vapor, Remote Sensing

\section{Introduction}

Clouds play a significant role in both the Earth's climate system and the ground-to-space radio communication system [1] [2]. By influencing the hydrological cycle and the radiation balance they can cause a wide variation in weather conditions [3]. These effects are even more severe in the tropical region due to the high probability for the occurrence of convective clouds. Unlike clouds found in other subtropical and temperate regions, these convective clouds are cumulus, extending over high vertical altitudes, and are heavy in liquid water content [4]. Therefore, cloud detection becomes a very important issue for a wide range of remote-sensing applications.

A stability index is intended to measure the ease with which an air parcel will rise through the atmosphere, using the parcel-to-environment temperature va- 
riance, a temperature difference of surface and upper-air, or the moisture content of the boundary layer [5]. There are four commonly used stability indices: 1) Lifted Index (LI), 2) $K$-Index $(K), 3)$ The Severe Weather Threat (SWEAT) Index and 4) The Convective Available Potential Energy (CAPE). These four indices predominantly identify thermodynamic instability, though the SWEAT index also includes components for wind veering and upper-level wind speed [6].

The cloud thickness or its extension in vertical direction is a crucial parameter to forecast rain or extreme rain. Nimbostratus and Cumulonimbus are the types of clouds which are responsible for all kinds of precipitation and cyclones. The "nimbo-" or "-nimbus" is a low-level cloud that has its bases below 2000 meters and can extend up to 6000 - 7000 meters above the Earth. "Nimbus" comes from the Latin word for "rain".

There are many approaches for detection of cloud presence in troposphere. The methods for determination of cloud base height from the Earth's surface have been developed in recent years. The quantity of water can be held and the amount of precipitation over certain area depends upon the depth or thickness of the cloud.

The CDI is introduced here to quantify the amount of precipitation over certain area. The index is also useful for determination of stability of the atmosphere over the specific region.

Radio-sounding observation data have been utilized to understand the cloud vertical structure since it provides observations of various important meteorological variables such as temperature, pressure, and relative humidity $(\mathrm{RH})$ along a vertical path. Apart from ceilometers observations the surface meteorological observations are also effective to retrieve the cloud base height $(\mathrm{CBH})$ [7]. The use of relative humidity as a constant threshold to sense the cloud base height and cloud thickness were developed in 1978. Cloud base height is the height of a layer where relative humidity first exceeds $95 \%$. The cloud thickness is determined by means of the points at which the relative humidity drops below $95 \%$ along the same cloud layer. Westwater et al. revised the relative humidity constant threshold to $90 \%$ instead of $95 \%$ by equating the ceilometer measurements with radiosonde humidity profiles of cloud base height [8]. Rossow and Schiffer suggested a technique with three relative humidity standards to detect the cloud vertical profile: 1) maximum relative humidity in a cloud of at least $87 \%, 2$ ) minimum relative humidity of at least $84 \%$, and 3) difference between cloud top and bottom layer should exceeds 3\% [9]. Salonen and Uppala proposed the cloud detection method using a pressure-dependent critical humidity function [10].

Water vapor plays a crucial role for the hydrological cycle in the Earth. The amount of water vapor suspended in the air and the temperatures of water vapor are the two vital elements contributing to the formation of clouds. Water vapor pressure (WVP) relying on these key factors should have some positive correlation with the cloud. 
Since the condensation of water vapor is a foundation of cloud formation, the correlation of the water vapor pressure with the cloud vertical structure should be very obvious. Thereby, water vapor pressure can be an accurate parameter for cloud detection. To determine the water vapor at different atmospheric levels, relative humidity and temperature data from radiosonde observations are used for calculating the spatial pressure of water vapor [11].

The approaches to detect the cloud base height and thickness using relative humidity or water vapor are quite successful. We utilized both crucial parameters of cloud formation i.e. relative humidity and perceptible water vapor to detect cloud presence conditions. We also use the altitude at which rain clouds are normally formed.

The new index for cloud detection CDI (cloud detection index) is introduced to detect the cloud as well as measure thickness of the cloud at given radio sounding site. The index is also useful to determine the atmospheric stability also. The cloud detection index is given by Equation (2.1).

\section{Data and Methodology}

We used the Radio-sounding observation data for Mumbai (VABB). The radio sounding site is situated at $19.0760^{\circ} \mathrm{N}, 72.8777^{\circ} \mathrm{E}$. We retrieved the radio sounding data from the year 2000 to 2017. We determined cloud detection index for the day of extreme rainfall events at Mumbai during year 2000 to 2017. As radiosonde observations have been widely utilized to understand and to model the cloud vertical structure since it is implemented with various sensors to measure important meteorological variables such as temperature, pressure, and relative humidity $(\mathrm{RH})$ along a vertical path. We considered mainly five pressure levels $1000 \mathrm{mb}, 850 \mathrm{mb}, 700 \mathrm{mb}, 500 \mathrm{mb}$ and $400 \mathrm{mb}$. These five levels represent Earth's surface, 1500 meters, 3000 meters, 5800 meters and 7500 meters respectively. The CDI are obtained for above selected altitudes from radiosonde observation of a particular day. If CDI has positive value it confirms the presence of cloud at that height. The depth or thickness of cloud is determined from difference of altitudes where CDI has positive values.

$$
\begin{aligned}
C D I_{i}= & \left\{R H_{i}-\left[1-\left[\left(\sigma-\sigma^{2}\right)+\left(\sqrt{3} \sigma^{2}-\frac{\sqrt{3}}{2} \sigma\right)-\left(\sqrt{3} \sigma^{3}-\frac{\sqrt{3}}{2} \sigma^{2}\right)\right]\right\}\right. \\
& -\left[R H_{i}\left(\mathrm{e}^{-a+b T_{i}+c T_{i}^{2}}\right)-\left(x \mathrm{e}^{-y H_{i}}\right)\right]
\end{aligned}
$$

where $\sigma=\frac{P_{i}}{P_{s}} P_{i} T_{i}$ and $H_{i}$ are the pressure, temperature and height of $i$ th layer of the atmosphere and $P_{s}$ is the surface pressure. Using the Equation (2.1) cloud presence is determined for the different layers like $850 \mathrm{mb}, 700 \mathrm{mb}$, $500 \mathrm{mb}$ and $400 \mathrm{mb}$. If $C D I_{850}-C D I_{400}$ is $>0$, then it's expected to have cloud which is responsible for extreme rain. If $C D I_{850}-C D I_{500}$ is $>0$, then it's expected to have cloud which is responsible for heavy rain. If $C D I_{850}-C D I_{700}$ is $>0$, then it's expected to have cloud for normal rain. Apart from CDI, there are 
two other stability indices, Convective Available Potential Energy (CAPE) and Convection Inhibition Energy (CINE), which support the cloud formation [12]. Variant nature of convection in the atmosphere depends upon dynamics as well as thermodynamics instability indices. The equivalent potential temperature is the crucial element for retrieving moist convective instability. Steeper the fall in the values of equivalent potential temperature, the presence of convective instability is more.

A critical element for atmospheric convection is the convective available potential energy $(C A P E)$, a measure of the vertical atmospheric instability the under moist convection. $C A P E$ is the work done by the buoyancy force on an air parcel lifted moist adiabatically through the atmosphere and is given by

$$
C A P E=-\int_{L F C}^{L B N}\left(T_{V P}-T_{V E}\right) R_{d} \mathrm{~d}(\ln P)
$$

where $R_{d}$ is the gas constant of dry air; $T_{V P}$ and $T_{V E}$ are respectively, the virtual temperatures of the parcel and the environment at pressure $P, L F C$ and $L N B$ are levels of free convection and neutral buoyancy. Deep clouds can develop due to the ascent of air from a given level, only if its $C A P E$ is greater than zero. When disturbances occur, precipitation, strong winds and downdrafts decrease the energy of the air from a given level, only if its $C A P E$ is greater than zero. Normally, air is not saturated to start with and a finite vertical displacement (a few hundred meters to a few kilometers) is needed for the rising air parcel to become saturated and reach the level of free convection. Some energy is required for this process, and is called convection inhibition energy (CINE).

$$
C I N E=-\int_{\text {surface }}^{L F C}\left(T_{V P}-T_{V E}\right) R_{d} \mathrm{~d}(\ln P)
$$

It is expected that a larger value of $C I N E$ means an increased barrier to convection. If $C I N E$ is large, deep clouds will not develop even if $C A P E$ is positive, while low values of $C I N E$ imply a favorable condition for convection [12].

The data source for this study is the Radiosonde data of Mumbai (VABB) station from year 1974 to 2017. The Observations are formally taken twice daily at 1200 and 0000 UTC. It provides vertical profile of wind direction, wind speed, height, temperature, pressure and humidity. The data are pre-processed to eliminate nil records and then they are processed to determine cloud detection index, stability indices like Lifted index (LI), K index, Convective Available Potential Energy (CAPE), Convection Inhibition Energy (CINE) and SWEAT Index. Cloud detection index (CDI) is determined for different pressure levels (altitudes) $1000 \mathrm{mb}, 850 \mathrm{mb}, 700 \mathrm{mb}, 500 \mathrm{mb}$ and $400 \mathrm{mb}$. These pressure levels represent Earth's surface, 1500 meters, 3000 meters, 5800 meters and 7500 meters respectively. We determined $C D I_{850}, C D I_{700}, C D I_{500}$ and $C D I_{400}$ using Equation 3.6. The obtained values of $C D I_{850}$ are compared with obtained values of $C D I_{700}, C D I_{500}$ and $C D I_{400}$. From the assessment the presence of cloud and its thickness are retrieved. We obtained the daily rainfall data for the station from the year 2000 to 2017 (17 years). We analyzed the rainfall data and identified the days on which the station (Mumbai) received the extreme rainfall. 


\section{Results}

The days of extreme or heavy rain at Mumbai are selected from the months June, July and August from the year 2000 to year 2017. These days are the days of extreme or heavily rain at radiosonde station (VABB). The extreme rainfall is the event where station receives more than $100 \mathrm{~mm}$ rain during 24 hours. Using Equation (2.4) the CDI is determined for various altitudes $(850 \mathrm{mb}, 700 \mathrm{mb}, 500$ $\mathrm{mb}$ and $400 \mathrm{mb}$ ) for selected days. Figures 1-3 illustrate the cloud detection Index (CDI) for June, July and August months.

The cloud thickness determined from the CDI for months of June, July and August are shown in Figure 4, Figure 5 and Figure 6 respectively. The rainfall at Mumbai for the selected days is also shown in Figure 7, Figure 8 and Figure 9 respectively. The CINE is determined over the station VABB one day before the extreme rain event at VABB. The values of Convection Inhibition Energy (CINE) are shown in Table 1. Figure 5 and Figure 6 illustrate that the cloud thickness is determined using CDI for radiosonde site VABB lies between 3000 meters to 6000 meters. There are three days in month of July for which

Cloud Detection Index (CDI) for June Month

$$
\square-\mathbf{- 5 0 - 0} \quad \square-\mathbf{0}=\quad \mathbf{5 0 - 1 0 0}
$$

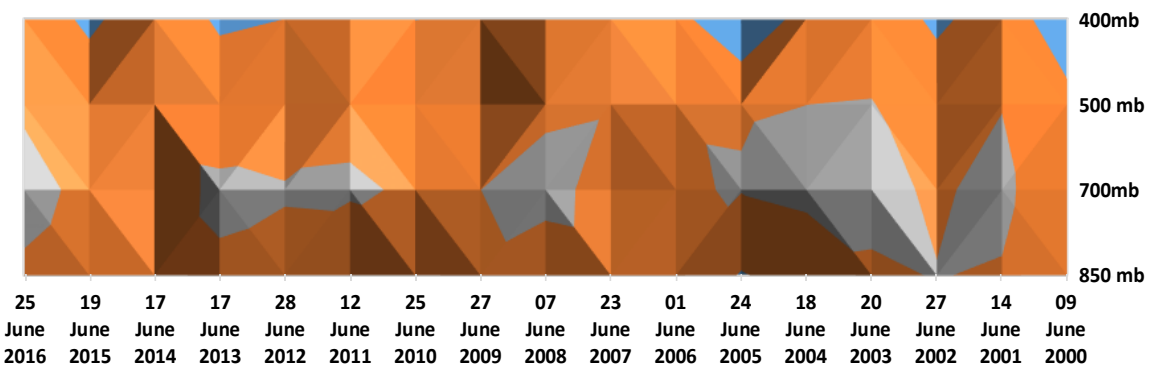

Figure 1. Cloud detection index (CDI) at VABB for month of June (Year 2000-Year 2017).

\section{Cloud Detection Index (CDI) for July Month}

$$
\square-100--50 \quad \square-50-0 \quad 0-50 \quad \square 0-100
$$

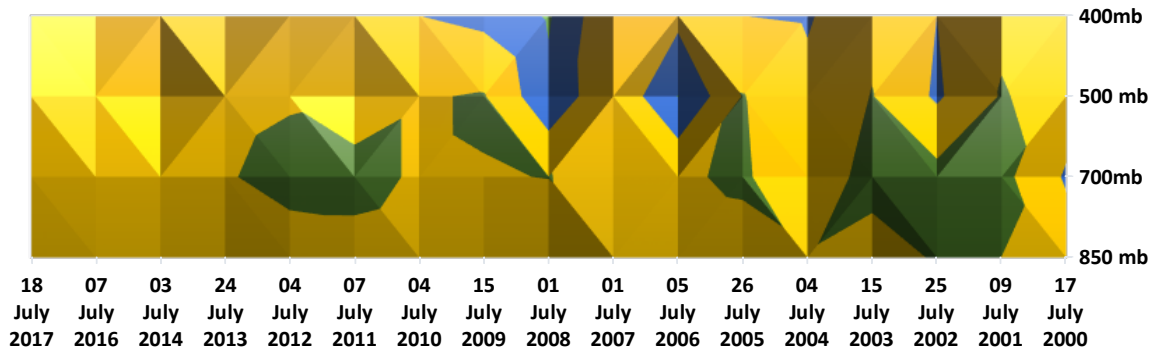

Figure 2. Cloud detection index (CDI) at VABB for month of July (Year 2000-Year 2017). 


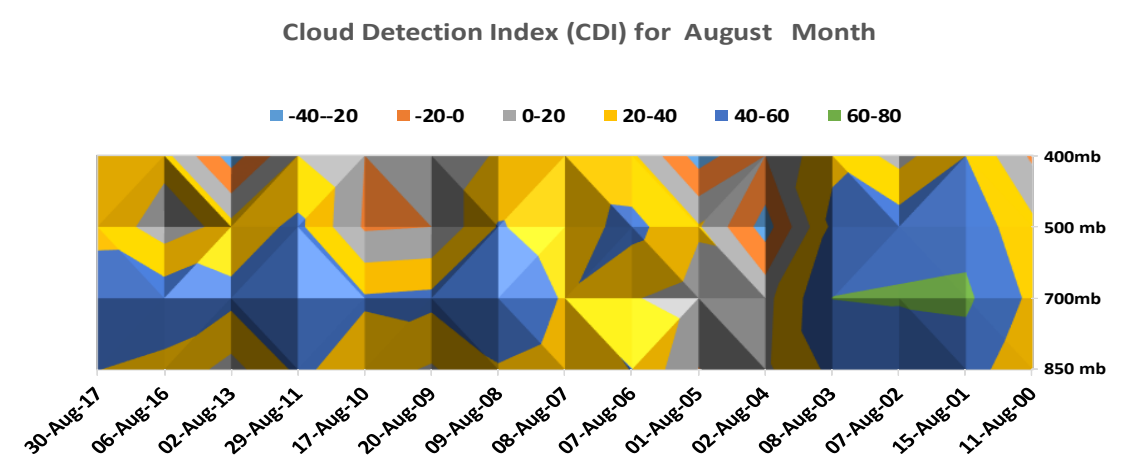

Figure 3. Cloud detection index (CDI) at VABB for month of August (Year 2000-Year 2017).

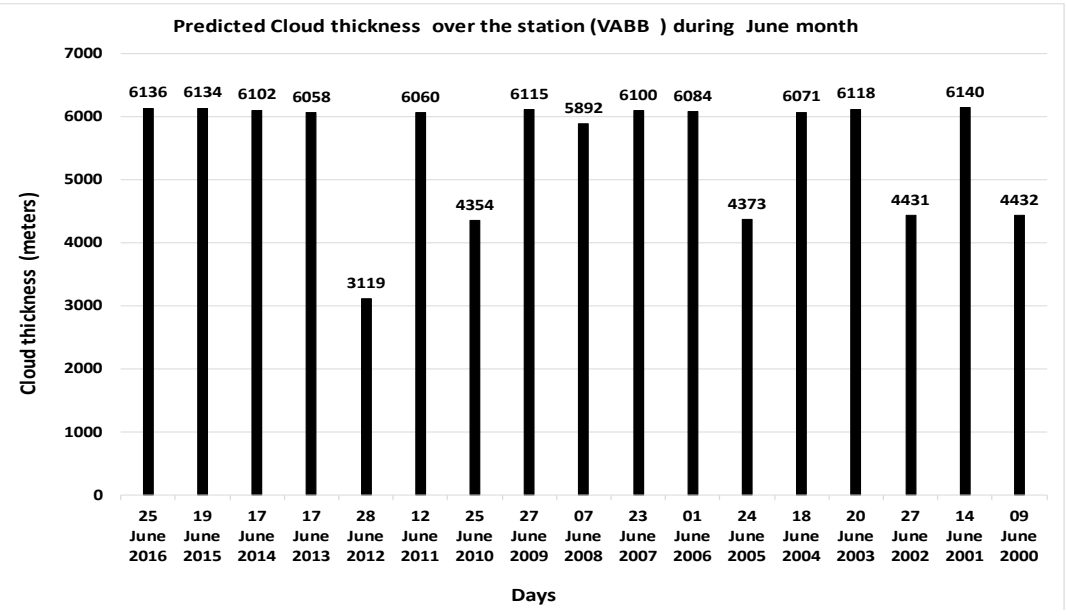

Figure 4. Cloud thickness at VABB for month of June (Year 2000-Year 2017).

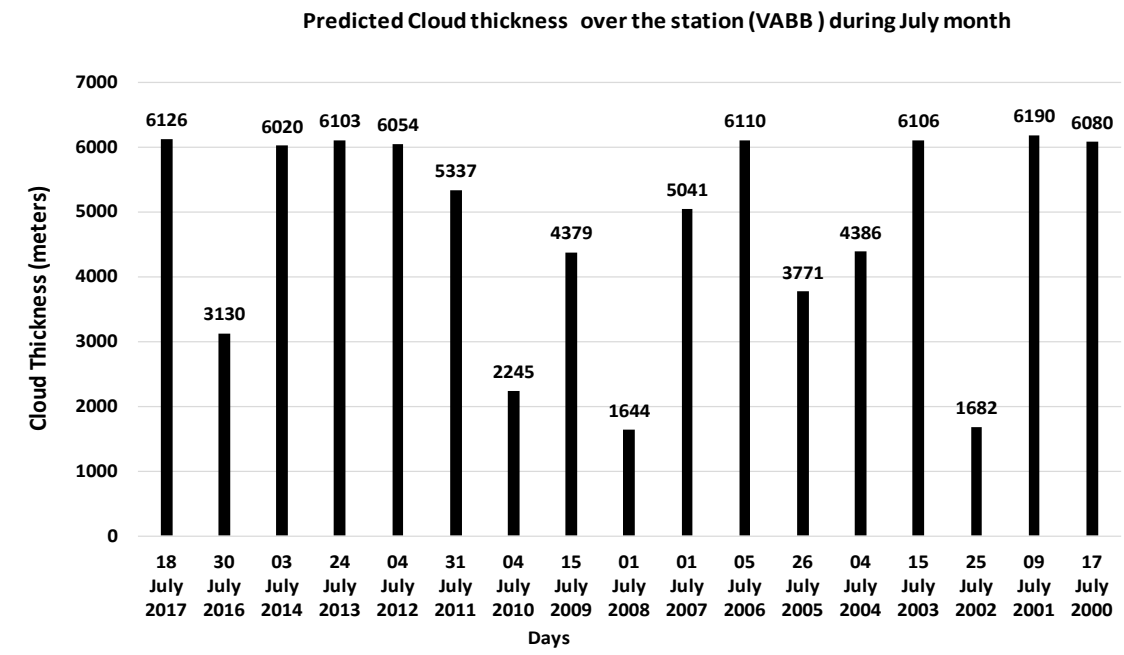

Figure 5. Cloud thickness at VABB for month of July (Year 2000-Year 2017).

the cloud thickness lies between 1500 meter to 3000 meters. There are four days in month August for which the cloud thickness falls between 1500 meters to 3000 meters. The derived value of CINE before 24 hours of the extreme rain event falls between 0 to -5 . 


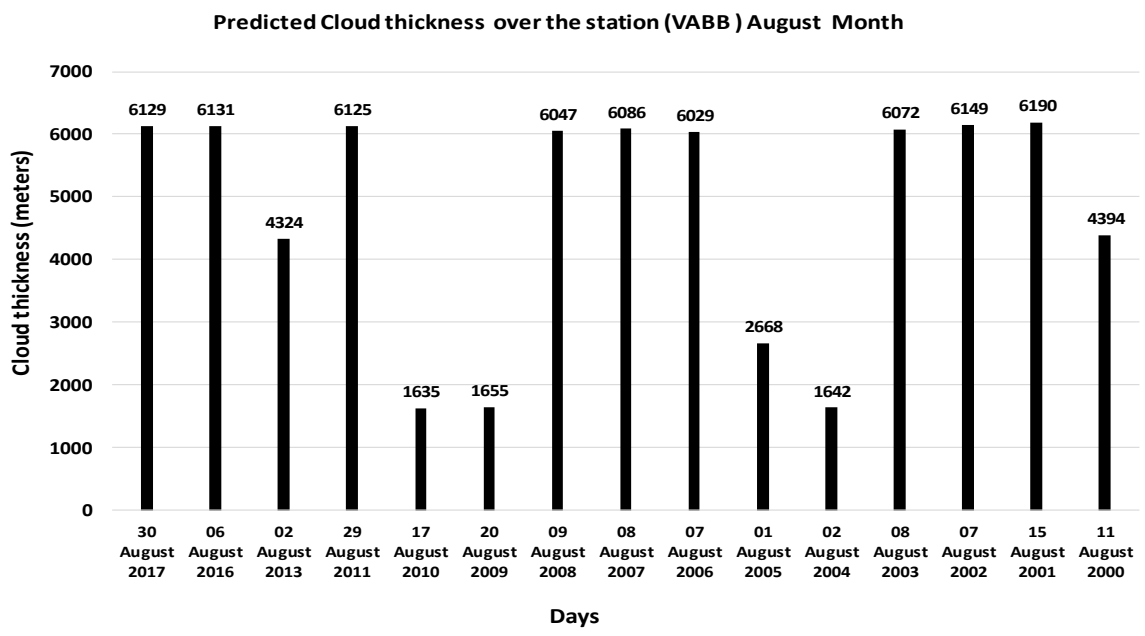

Figure 6. Cloud thickness at VABB for month of August (Year 2000-Year 2017).

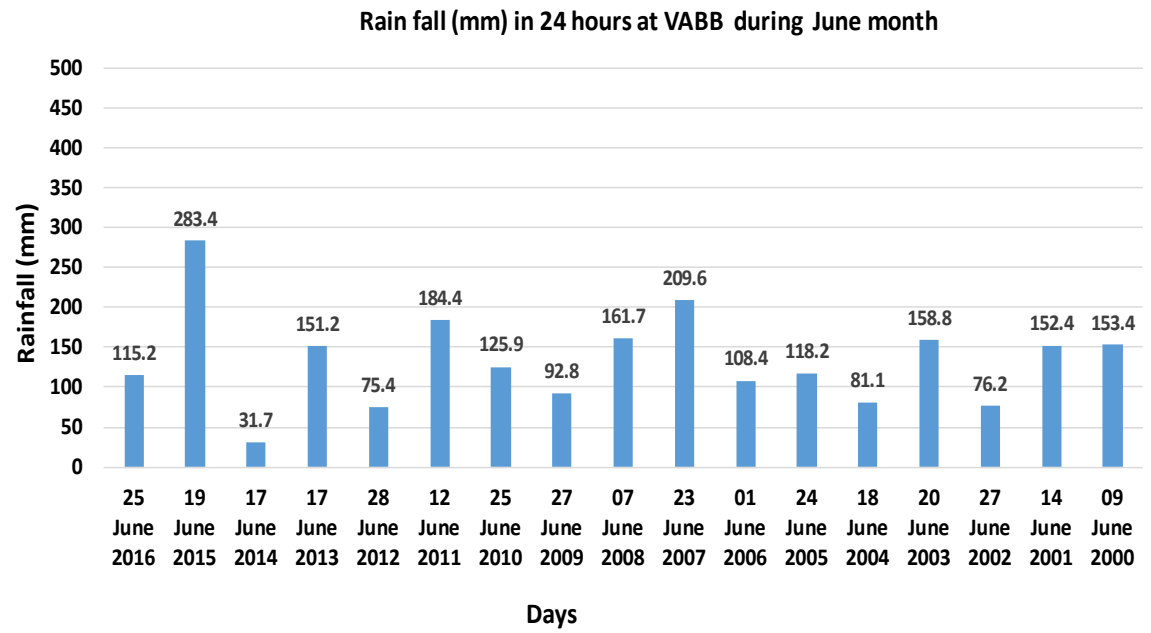

Figure 7. Extreme rainfall events at VABB for month of June (Year 2000-Year 2017).

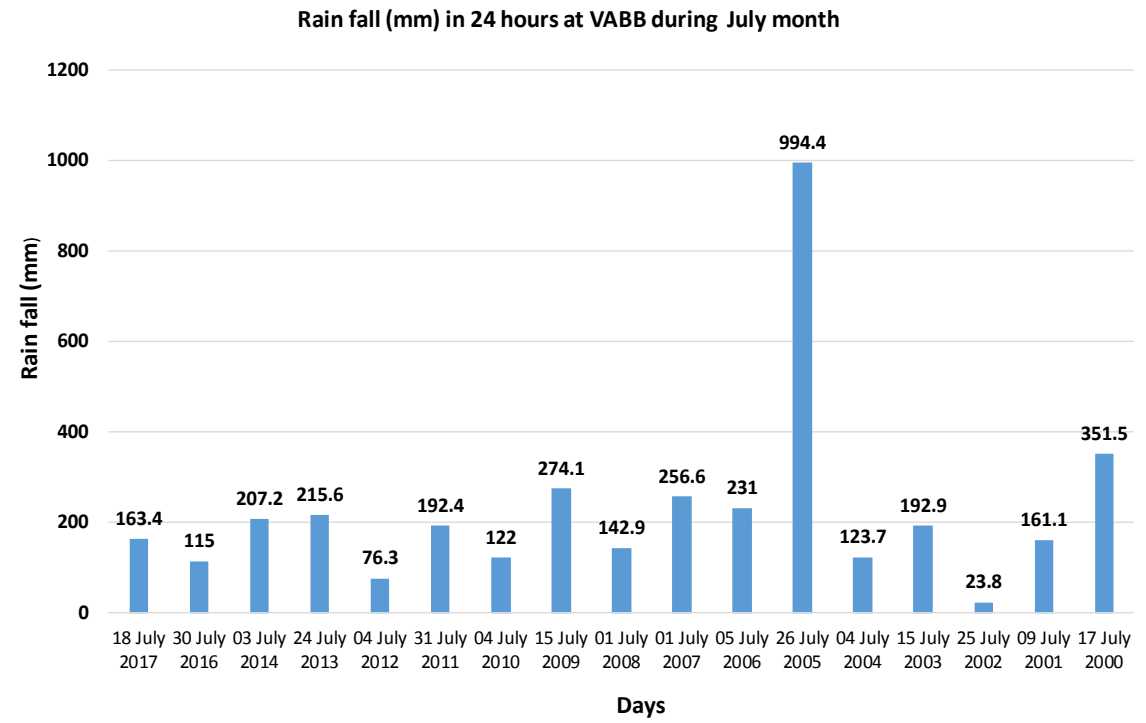

Figure 8. Extreme rainfall events at VABB in the month of July (Year 2000-Year 2017). 


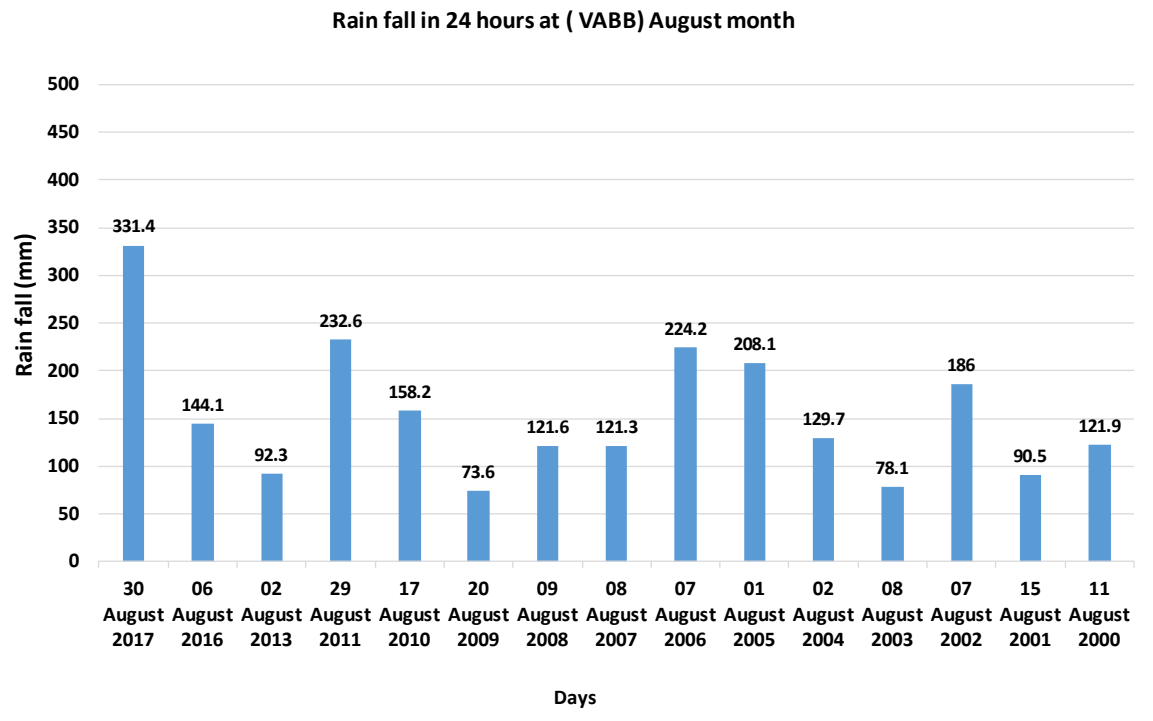

Figure 9. Extreme rainfall events at VABB in the month of August (Year 2000-Year 2017).

Table 1. Values of CINE before 24 hours of extreme rain events at VABB.

\begin{tabular}{cccccc}
\hline $\begin{array}{c}\text { Date of Extreme } \\
\text { Rain at VABB }\end{array}$ & $\begin{array}{c}\text { CINE at } \\
\text { VABB before } \\
\text { 24 Hours }\end{array}$ & $\begin{array}{c}\text { Date of } \\
\text { Extreme Rain } \\
\text { at VABB }\end{array}$ & $\begin{array}{c}\text { CINE at } \\
\text { VAB before } \\
\text { 24 Hours }\end{array}$ & $\begin{array}{c}\text { Date of Extreme } \\
\text { Rain at VABB }\end{array}$ & $\begin{array}{c}\text { CINE at VABB } \\
\text { before 24 Hours }\end{array}$ \\
\hline 25 June 2016 & -0.21 & 18 July 2017 & -6.52 & 30 August 2017 & -0.11 \\
19 June 2015 & -0.04 & 30 July 2016 & -0.13 & 06 August 2016 & -0.08 \\
17 June 2014 & 0 & 03 July 2014 & -3.25 & 02 August 2013 & 0 \\
17 June 2013 & 0 & 24 July 2013 & 0 & 29 August 2011 & 0 \\
28 June 2012 & 0 & 04 July 2012 & -4.44 & 17 August 2010 & 0 \\
12 June 2011 & 0 & 31 July 2011 & 0 & 20 August 2009 & 0 \\
25 June 2010 & -1.12 & 04 July 2010 & NA & 09 August 2008 & -1.38 \\
27 June 2009 & -2.14 & 15 July 2009 & -1.86 & 08 August 2007 & 0 \\
07 June 2008 & -0.1 & 01 July 2008 & -0.01 & 07 August 2006 & 0 \\
23 June 2007 & -0.46 & 01 July 2007 & 0 & 01 August 2005 & 0 \\
01 June 2006 & -2.49 & 05 July 2006 & 0 & 02 August 2004 & -0.14 \\
24 June 2005 & -2.98 & 26 July 2005 & 0 & 08 August 2003 & -1.15 \\
18 June 2004 & -0.8 & 04 July 2004 & -11.5 & 07 August 2002 & 0 \\
20 June 2003 & 0 & 15 July 2003 & -0.025 & 15 August 2001 & 0 \\
27 June 2002 & -1.47 & 25 July 2002 & -0.23 & 11 August 2000 & -0.05 \\
14 June 2001 & -1.68 & 09 July 2001 & -53.89 & NA & NA \\
09 June 2000 & -0.25 & 17 July 2000 & 0 & NA & NA \\
\hline
\end{tabular}

\section{Conclusions}

If the precipitation is more than $100 \mathrm{~mm}$ in a day ( 24 hours), then it is defined as extreme rain. The cloud which can hold huge amounts of perceptible water can result in extreme rain. The clouds having thickness more than 3000 meters in vertical direction are able to hold enormous amounts of perceptible water. So if 
the thickness of the cloud over any location or area is more than 3000 meters, the forecast can be made for extreme rain over that area. The cloud thickness determination is a vital process for forecasting the extreme rain events.

In this study the cloud thickness is retrieved using CDI for selected days of extreme rain at radiosonde site VABB. The results illustrate that the obtained values of cloud thickness range from 3000 meters to 6000 meters. Such thick cloud and low value of CINE are observed during each event of extreme rain at VABB. The CDI can be included with other indices for determining atmospheric stability and forecasting the extreme weather events. If $C D I_{850}-C D I_{400}$ is $>0$, then it's expected to have a cloud which is responsible for extreme rain. If $C D I_{850}-C D I_{500}$ is $>0$, then it is expected to have a cloud which is responsible for heavy rain. If $C D I_{850}-C D I_{700}$ is $>0$, then it's expected to have a cloud for normal rain. The CDI along with CINE can be efficacious for extreme rainfall which is more frequent nowadays in Indian subcontinent.

\section{References}

[1] Maestri, T. and Holz, R.E. (2009) Retrieval of Cloud Optical Properties from Multiple Infrared Hyperspectral Measurements: A Methodology Based on a Line-By-Line Multiple-Scattering Code. IEEE Transactions on Geoscience and Remote Sensing, 47, 2413-2426. https://doi.org/10.1109/TGRS.2009.2016105

[2] Maghrabi, A. and Al Dajani, H.M. (2013) Estimation of Precipitable Water Vapour Using Vapour Pressure and Air Temperature in an Arid Region in Central Saudi Arabia. Journal of the Association of Arab Universities for Basic and Applied Sciences, 14, 1-8. https://doi.org/10.1016/j.jaubas.2012.11.001

[3] Miller, R.C. (1972) Notes on Analysis and Severe-Storm Forecasting Procedures of the Air Force by Global Weather Central.

[4] Hirsch, E., Agassi, E. and Koren, I. (2011) A Novel Technique for Extracting Clouds Base Height Using Ground Based Imaging. Atmospheric Measurement Techniques, 4, 117-130. https://doi.org/10.5194/amt-4-117-2011

[5] DeRuberts, D. (2006) Recent Trends in Four Common Stability Indices Derived from U.S. Radiosonde Observations. Journal of Climate, 19, 309-323. https://doi.org/10.1175/JCLI3626.1

[6] Gottlieb, R.J. (2009) Analysis of Stability Indices for Severe Thunderstorms in the Northeastern United States. Honors Thesis, Cornell University, Ithaca, 23 p.

[7] Shukla, K.K., Niranjan Kumar, K., Phanikumar, D.V., et al. (2016) Identification of the Cloud Base Height over the Central Himalayan Region: Intercomparison of Ceilometer and Doppler Lidar. Atmospheric Measurement Techniques, 1-26. https://doi.org/10.5194/amt-2016-162

[8] Westwater, E.R., Han, Y., Shupe, M.D. and Matrosov, S.Y. (2001) Analysis of Integrated Cloud Liquid and Precipitable Water Vapor Retrievals from Microwave Radiometers during the Surface Heat Budget of the Arctic Ocean Project. Journal of Geophysical Research: Atmospheres, 106, 32019-32030.

https://doi.org/10.1029/2000JD000055

[9] Rossow, W.B. and Schiffer, R.A. (1999) Advances in Understanding Clouds from ISCCP. Bulletin of the American Meteorological Society, 80, 2261-2287. https://doi.org/10.1175/1520-0477(1999)080<2261:AIUCFI>2.0.CO;2

[10] Salonen, E. and Uppala, S. (1991) New Prediction Method of Cloud Attenuation. 
Electronics Letters, 27, 29-31. https://doi.org/10.1049/el:19910687

[11] Yuan, F., Lee, Y.H., Meng, Y.S. and Ong, J.T. (2016) Water Vapor Pressure Model for Cloud Vertical Structure Detection in Tropical Region. IEEE Transactions on Geoscience and Remote Sensing, 54, 5875-5883.

https://doi.org/10.1109/TGRS.2016.2574744

[12] Jenamani, R.K., Bhan, S.C. and Kalsi, S.R. (2006) Observational/Forecasting Aspects of the Meteorological Event That Caused a Record Highest Rainfall in Mumbai. Current Science, 90, 1344-1362. https://doi.org/10.1016/j.neucom.2007.07.014 